\title{
AS TRAJETÓRIAS ESCOLARES: PERCEPÇÕES DE CRIANÇAS/ALUNOS E PROFESSORAS
}

\author{
THE TRAJECTORIES OF SCHOOL: PERCEPTIONS OF CHILDREN / STUDENTS \\ AND TEACHERS
}

Luciana Ponce Bellido GIRALDI ${ }^{1}$

RESUMO: Pode-se dizer que há dois eixos centrais que perpassam o conceito de infância. O primeiro é a socialização, atrelada principalmente às instituições sociais, como a escola e a família, em que adultos ensinam maneiras de ser e agir em sociedade para a manutenção e coesão da mesma. E, o segundo, é a individualização, na qual a criança é um sujeito de direitos e um protagonista social. Permeados pela socialização e individualização, entender as percepções que crianças/alunos podem formular sobre o próprio processo escolar se tornou um eixo de fundamental importância para a compreensão de trajetórias escolares. De tal modo, o objetivo deste texto consistiu em apreender a percepção de duas crianças/alunos sobre as experiências e desempenhos escolares apresentados por eles no decorrer de parte do Ensino Fundamental I e relacionar tais percepções a de professores que ministraram aulas para eles. Trata-se de uma pesquisa de mestrado e doutoramento que acompanhou em 2009, $2011 \mathrm{e}$ 2012 - no $2^{\circ}, 4^{\circ}$ e $5^{\circ}$ ano, uma menina e um menino, com sete a dez anos de idade, que foram indicados no $2^{\circ}$ ano pela professora responsável pela turma deles como estudantes que apresentavam desempenhos medianos. Configurou-se como um estudo longitudinal qualitativo que utilizou como instrumento de coleta de dados a análise de documentos escolares, observações de aulas e entrevistas com professores e alunos (neste caso foram empregadas estratégias lúdicas). Além disso, os estudantes também responderam a um questionário e produziram um texto autobiográfico para relatar as experiências que mantinham com a escola. Foi possível concluir que os dois alunos expuseram suas percepções sobre os desempenhos escolares e experiências vivenciadas no contexto escolar desde o $2^{\circ}$ ano de escolarização, as quais nem sempre corroboraram com indicações dadas por professores. Os dois alunos/crianças demonstraram preocupações com a possibilidade de acesso a determinadas escolas, em detrimento de outras, na sequência do processo de escolarização.

PALAVRAS-CHAVE: Trajetórias escolares. Percepções de alunos/crianças. Ensino Fundamental I.

ABSTRACT: It can be said that there are two central themes that underlie the concept of childhood. The first is the socialization, linked mainly to social institutions such as the school and the family, where adults teach ways of being and acting in society for the maintenance and cohesion of the same. And the second is the individualization, in which the child is a subject of rights and a social protagonist. Pervaded by the socialization and individualization, understanding the perceptions that children / students can make on their own educational process has become an axis of fundamental importance for the understanding of school trajectories. So, the aim of this paper is to learn the perception of

1 Fundação Carlos Chagas (FCC), São Paulo - SP - Brasil. Estagiário Pós-Doutoral. E-mail: luluponce@gmail.com. 
two children / students on school experiences and performances presented by them during part of the elementary school and to relate these perceptions of teachers who gave classes for them. This study has provided data a master's and doctoral research that followed in 2009, 2011 and 2012 - the 2nd, 4th and 5th year, a girl and a boy, with seven to ten years old, who were appointed in the 2nd year by the teacher responsible for their class as students who had middling performances. It appears as a qualitative longitudinal study that used as data collection instrument analysis of school documents, lesson observations and interviews with teachers and students (in this case playful strategies were employed). In addition, students also answered a questionnaire and produced an autobiographical text to report the experiences they had with the school. It was concluded that the two students expressed their perceptions about school performance and life experiences in the school context from the 2nd year of schooling, which not always corroborated indications given by teachers. The two students / children have shown concern with the possibility of access to certain schools at the expense of others, following the schooling process.

KEYWORDS: School trajectories. Perceptions of students / children. Elementary School I.

\section{Introdução}

Segundo o Estatuto da Criança e do Adolescente (BRASIL, 1990), Lei $\mathrm{n}^{\mathbf{0}}$ 8.069, criança é toda pessoa até os doze anos de idade e goza de todos os direitos fundamentais disponíveis aos homens, o que, é claro, inclui o direito à educação.

\footnotetext{
Art. $4^{\circ}$ É dever da família, da comunidade, da sociedade em geral e do poder público assegurar, com absoluta prioridade, a efetivação dos direitos referentes à vida, à saúde, à alimentação, à educação, ao esporte, ao lazer, à profissionalização, à cultura, à dignidade, ao respeito, à liberdade e à convivência familiar e comunitária.
}

Pensando na história do conceito de infância, Sarmento (2005), afirma que se afere uma percepção "negativa" de tal fase, visto que infância seria compreendida como a idade do não-falante, o aluno remeteria a concepção de sem-luz e criança seria entendida enquanto alguém que está em processo de criação, de dependência.

O clássico estudo iconográfico feito por Ariès (1981) concluiu que, em geral e considerando as camadas mais abastadas da população, até a Idade Média, não havia na sociedade o conceito de infância. Já na Idade Moderna a criança passou a ser vista como um “adulto em gestação", a família também sofreu significativas modificações com o nascimento da vida privada e a valorização da intimidade. A chegada dessas duas novidades seria considerada como a passagem para uma supervalorização da infância, sendo que esta deveria 
ser protegida do mundo dos adultos, havendo espaços e percepções destinadas especialmente a elas.

Essa concepção de infância como uma fase de proteção, de cuidados e mesmo seguindo imagens comuns, como crianças que brincam, felizes, que circulam socialmente pelos meios de comunicações e pelas indústrias, são privilégios vivenciados por algumas crianças.

Conforme Kramer (2007) crianças são sujeitos sociais e históricos, selados pelas desigualdades sociais, pelas contradições e paradoxos da sociedade na qual estão inseridos. Neste sentido, Gimeno Sacristán (2005) relata a não existência de modelos de infâncias, para ele há modos de viver essa fase da vida. Sendo comum a infância ser concebida e lida pelos adultos.

Entretanto, na literatura percebe-se uma corrente que almeja romper com essa tendência de ler a infância pelos olhos adultos. Estudos num campo em expansão intitulado de Sociologia da Infância entendem o termo infância como um conceito, sendo ser criança um sujeito dessa ideia, compreendido como um ator social, não mais o reflexo do pensamento de adultos (SARMENTO, 2005).

Somado a isso, pesquisas sobre trajetórias escolares, como a de Zago (2000), Viana (2000) e Portes (2001), identificaram ações dos próprios estudantes para a composição de trajetórias diferenciadas, o que estaria atrelada à percepção dos indivíduos como ativos em seus processos de socialização.

Recentemente, alguns estudos desenvolvidos nos Estados Unidos têm analisado a participação de alunos, desde a Educação Infantil, como agentes no processo de reprodução de classes (STREIB, 2011). Eles entendem que os estudantes são ativos em suas próprias socializações e capazes de exercer influências sobre as atitudes dos adultos, o que teria implicações nas teorias do capital cultural e da reprodução social; já que estas entenderam os alunos como recipientes de oportunidades criadas por familiares e professores ${ }^{2}$.

Streib (2011) organizou observações junto a uma turma pré-escolar que atendia alunos oriundos da classe trabalhadora e da classe média-alta. Ela concluiu que estes estudantes costumavam interromper mais as aulas, pedir ajuda e argumentar com mais frequência do que os estudantes da classe trabalhadora. Assim, os primeiros tinham mais oportunidades de

${ }^{2}$ Calarco (2011) assumiu que nos estudos de Bourdieu, por exemplo, houve um pequeno reconhecimento de atitudes adotadas pelos alunos como estratégias empregadas para mudar as trajetórias deles, contudo não foi agregado suporte a tais alegações e mantiveram as análises nas oportunidades criadas pelos familiares dos alunos para prover trajetórias escolares. 
desenvolver as habilidades linguísticas deles em detrimento do que acontecia com os alunos da classe trabalhadora.

Dentro desta perspectiva, Calarco (2011) organizou um estudo etnográfico e longitudinal, que por meio de notas de campo questionou se, quando e como as crianças da classe média e trabalhadora costumavam pedir ajuda aos professores e criar oportunidades para aprender. Esta pesquisa coletou dados entre alunos de uma escola pública de ensino fundamental que tinha uma minoria de $25 \%$ deles, oriundos da classe trabalhadora. Neste contexto, a pesquisadora acompanhou quatro turmas, do terceiro ao quinto ano, junto aos diferentes professores que ministravam aulas para elas. A coleta de dados ocorreu entre 2008 e 2011, sendo que a pesquisadora visitava a escola pelo menos duas vezes na semana, durante diferentes atividades. Foi empregado como coleta de dados entrevistas, observações e questionários; concluindo que as crianças da classe trabalhadora pediam menos ajuda aos professores e usavam diferentes estratégias para isso, visto que demonstravam mais receio de fazê-lo. As crianças da classe média obtinham mais ajuda dos professores, se aproximavam facilmente destes e gastavam menos tempo à espera de apoio, assim eram mais capazes de realizarem atividades, por isto criavam suas próprias vantagens e mantinham desigualdades em sala de aula.

Diante do exposto, a presente pesquisa teve como objetivo apreender a percepção de duas crianças/alunos sobre as experiências e desempenhos escolares apresentados por eles no decorrer de parte de suas trajetórias no Ensino Fundamental I e relacionar tais percepções a de professores que ministraram aulas para eles.

Justifica-se que tomar as percepções de crianças/alunos sobre o próprio desempenho e experiências escolares pode trazer subsídios para compreender as perspectivas construídas pelos sujeitos e relacionar a socialização, atrelada principalmente às instituições sociais, como a escola e a família, em que adultos ensinam maneiras de ser e agir em sociedade para a manutenção e coesão da mesma; e a individualização, na qual a criança é um sujeito de direitos e um protagonista social.

\section{Métodos}

Trata-se de uma pesquisa qualitativa, de caráter longitudinal de painel, definida assim conforme Hakim (1997) por acompanhar os mesmos sujeitos durante um período de tempo e contar com sucessivas coletas de informações. 
Participaram desta pesquisa dois alunos, os quais foram acompanhados enquanto cursavam o segundo ano, em 2009 (GIRALDI, 2010) e depois novamente foram localizados quando estavam matriculados no quarto e quinto ano, respectivamente em 2011 e 2012 (GIRALDI, 2014).

Quando a pesquisa começou, em 2009, os estudantes tinham sete anos e quando terminou em 2012, eles contavam com dez anos de idade. Durante esta trajetória escolar, eles estiveram matriculados em uma escola de Ensino Fundamental I, localizada em um bairro periférico de uma cidade do interior do Estado de São Paulo.

Chegou-se a tal escola após a indicação da Secretária Municipal de Educação do munícipio, diante da apresentação e aceitação de um projeto de pesquisa. Neste, havia o intuito de estudar concepções e expectativas de professores, familiares e alunos sobre os desempenhos escolares destes no Ensino Fundamental I.

Neste momento, optou-se por enfatizar estudos de casos construídos junto aos primeiros anos da escolarização, mais especificamente, o segundo ano do Ensino Fundamental I, momento escolhido para ser investigado por dois motivos: 1 . O primeiro ano escolar, no município pesquisado, ficava em uma escola de Educação Infantil, o que não remetia, sobretudo aos familiares, a um rompimento com a Educação Infantil. 2. Esperava-se ter informações sobre notas atribuídas aos estudantes, o que ocorria apenas no segundo ano escolar.

Diante disso, após autorização da secretária de educação do município, com a indicação da escola a ser estudada, a pesquisadora foi até a unidade de ensino e conversou com a equipe gestora, a qual sugeriu que fosse feito um convite aos quatro professores que ministravam aulas aos segundos anos naquela instituição, o que foi feito durante reunião de Horário de Trabalho Pedagógico Coletivo (HTPC). Apenas uma destas professoras aceitou o convite.

Esta docente contava com 27 anos de idade, seis anos de experiência e era responsável por uma turma no período da manhã naquela escola. Possuía magistério, graduação em Pedagogia e pós-graduação Latu Senso concluída.

$\mathrm{Na}$ opinião dela, o segundo ano em que atuava era uma turma com um desempenho adequado, que se destacava entre as outras turmas da escola, pois, embora ali também houvesse estudantes que vivenciavam dificuldades para aprender, ela compreendeu que se tratava de um grupo interessado, que queria participar da aula.

A partir desta professora, foram selecionados os alunos e respectivos familiares que compuseram a investigação. A pesquisadora pediu que a docente indicasse seis alunos, 
entendidos por ela como casos de alto, médio e baixo desempenhos escolares. Dois estudantes representantes de cada grupo, sendo uma menina e um menino ${ }^{3}$.

Neste momento, será discutido as percepções de desempenho escolar dos alunos indicados como casos de desempenho mediano. As famílias dos alunos alvitrados com desempenhos medianos pareciam ter experiências bastante diferenciadas. O garoto, chamado aqui de Messias $^{4}$, advinha de uma família nuclear e era filho único. Residiam numa casa própria, além disso, a mãe cursou até o ensino fundamental e o pai concluiu o ensino médio. Já a menina, chamada de Mani, fazia parte de uma família ampliada, constituída pela avó e pelo avô $\hat{0}^{5}$, que eram responsáveis por três netos. A avó havia cursado a primeira série, o avô era analfabeto. Eles também residiam em casa própria.

A professora que foi responsável pela turma dos estudantes acompanhados em 2011, quando cursavam o quarto ano escolar, cursou duas especializações, tinha 47 anos de idade e 25 anos de experiência. A docente que atuou em 2012 contou com uma especialização, ela tinha 39 anos de idade e 13 anos de experiência na área.

Quadro 1: Participantes da pesquisa.

\begin{tabular}{|l|l|}
\hline \multicolumn{1}{|c|}{ Grupos } & \multicolumn{1}{c|}{ Sujeitos } \\
\hline Alunos & Mani \\
& Messias \\
\hline Familiares & Avó de Mani \\
& Mãe de Messias \\
\hline Professoras & $2^{\mathbf{o}}$ ano \\
& $4^{\mathbf{o}}$ ano \\
& $5^{\mathbf{o}}$ ano \\
\hline
\end{tabular}

Fonte: Dados da pesquisa.

O processo de coleta dos dados ocorreu em dois momentos. Primeiramente, em 2009, (GIRALDI, 2010), durante o mestrado e, posteriormente em 2011 e 2012 referente ao doutoramento (GIRALDI, 2014).

No doutorado (GIRALDI, 2014) houve a intenção de acompanhar parte do processo de escolarização dos mesmos sujeitos, após perceber, em revisões bibliográficas, que isto não seria recorrente, se fazendo presente raros dados processuais de pesquisas (LAHIRE, 2004; PAYET, 2005; ABRANTES, 2005).

${ }^{3}$ Conforme a professora, não havia na sala meninas com baixo desempenho escolar, apenas meninos, por isto, ela indicou dois garotos neste caso.

${ }^{4}$ Os nomes são fictícios.

${ }^{5}$ A mãe desta garota havia sido presa por tráfico de drogas. 
Por isso, em 2011 a pesquisadora retornou a escola onde coletou dados em 2009 e localizou os alunos que fizeram parte do primeiro estudo, os quais permaneciam na mesma instituição. Então, ela entrou em contato com os professores que ministravam aulas para os estudantes acompanhados naquele momento da trajetória escolar, quando cursavam o $4^{\circ}$ ano, e voltou a falar com os familiares dos mesmos, pedindo autorização para a continuação da investigação. Todos aceitaram contribuir com a pesquisa.

Como instrumentos de coleta de dados, em 2009, foram organizadas entrevistas com professores, familiares e alunos; assim como houve observações de aulas e análise de documentos escolares (como boletins e históricos). Entre os anos de 2011 e 2012 foram empregados como instrumentos de coleta de dados: entrevistas com professores, familiares e alunos, observações de aulas e de reuniões de conselhos de escola. Existiu também a obtenção de documentos que explicitassem a organização das instituições de ensino e, ocorreu ainda, a aplicação de um questionário (respondido pelos alunos e/ou familiares) e a produção de uma história autobiográfica (escrita pelos alunos, como tarefa de casa, conforme estabelecido pela professora. A pesquisadora entregou alguns itens como roteiro para que escrevessem o texto ${ }^{6}$.

Vale ressaltar que as entrevistas com os alunos ocorreram em quatro momentos: 1. Início e final do ano de 2009, 2. Em 2011 e 3. Em 2012.

No primeiro momento em 2009 houve a utilização de materiais para formulação de rostos, imagens-ideias para facilitar a conversa com as crianças, para que pudessem falar e ao mesmo tempo brincar com a formulação de imagens representativas.

As peças usadas foram compostas pela pesquisadora empregando E.V.A. (Etil Vinil Acetato), lã, moldes e tesoura; e incluiu também as peças de um jogo chamado "Brincando com caretas" Toyster. Informa-se que este jogo foi escolhido unicamente por suas peças/imagens relacionadas a rostos expressando sentimentos diversos.

Figura 1: Ilustração da caixa do jogo.

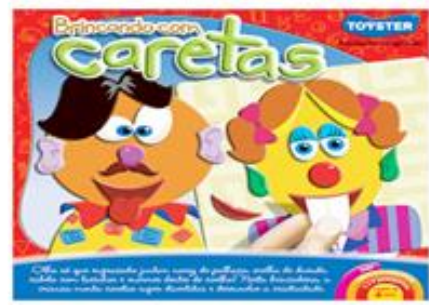

Fonte: Elaboração própria

${ }^{6}$ Para mais informações sobre os roteiros de entrevista, observação ou para a escrita da autobiografia, consultar Giraldi $(2014,2010)$. 
Figura 2: Materiais utilizados

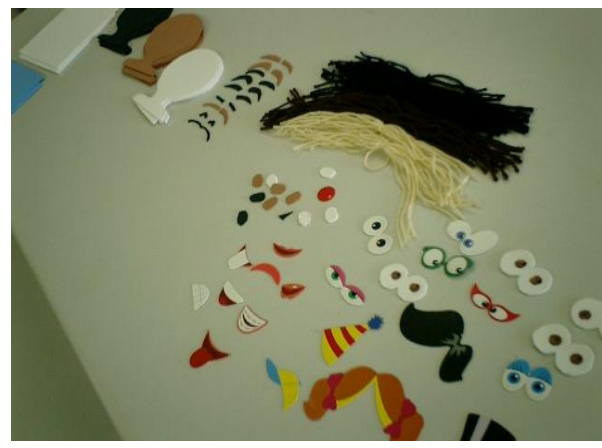

Fonte: Elaboração própria

As entrevistas realizadas no início do ano com as crianças estavam divididas em quatro partes: O eu, Meu amigo, A Escola, A família. Essas partes foram relacionadas à organização de rostos, os quais foram fotografados por uma câmera digital. Segue um exemplo ilustrativo dos rostos produzidos por um aluno.

Figura 3: Eu

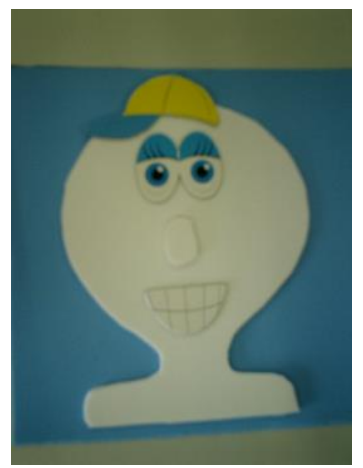

Fonte: Elaboração própria.

Figura 5: Escola

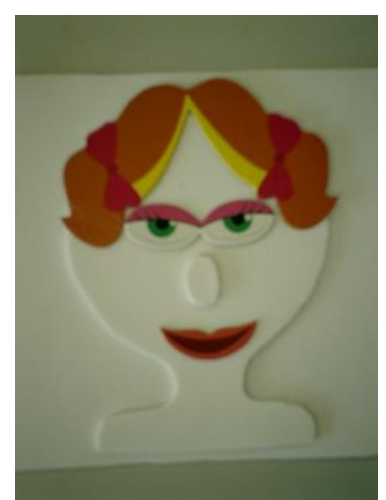

Fonte: Elaboração própria.
Figura 4: Amigo

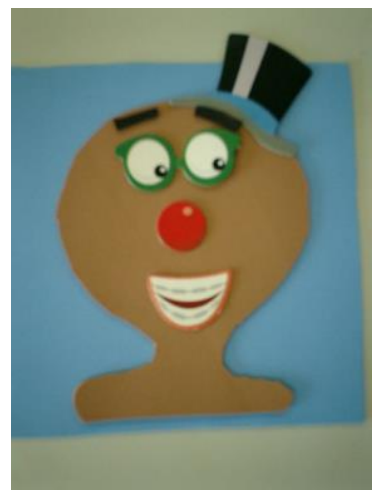

Fonte: Elaboração própria.

Figura 6: Família

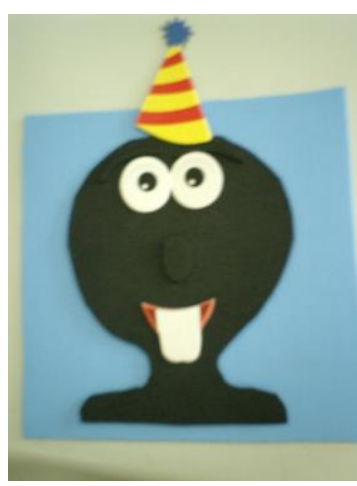

Fonte: Elaboração própria. 
No final do ano letivo de 2009 uma nova entrevista foi realizada com as crianças para cotejar concepções sobre o próprio desempenho escolar e expectativas para o próximo ano, mas neste momento, houve uma conversa rápida, sem uso de materiais de suporte.

Conforme Bogdan e Biklen (1994) entrevistar crianças representa um desafio diferenciado para muitos investigadores, elas podem ficar inibidas diante do pesquisador ou mesmo procurar a aprovação dele. Sobre isso, um observador notou que as crianças concebiam-no como uma pessoa externa e adulta, o que afetava os dados obtidos, sendo preciso encontrar meios para conseguir adentrar no mundo delas.

Em Giraldi (2014) foi vivenciada a necessidade de buscar suportes para falar com os alunos. Acreditou-se que retomar o contato com os estudantes gerou certas desconfianças da parte deles, às vezes pareciam envergonhados ou preocupados com a presença da pesquisadora em sala de aula, conversando com familiares e professoras.

Em 2011, alguns alunos ficaram acanhados e não relataram tanto quanto esperado sobre as vivencias deles após 2009, mesmo com o cuidado de sempre lembrá-los que tudo o que fosse dito não seria exposto a ninguém.

Por isto, inspirando-se no mestrado (GIRALDI, 2010) ocorreu a busca por um suporte que auxiliasse naquele momento.

Dessa maneira, optou-se por agregar à entrevista com os alunos um suporte que ampliasse a conversa e acrescentasse temas gerais para que eles pudessem falar. Com esses objetivos, foi incluído o jogo Brincando com palavras ${ }^{7}$.

Primeiro foi estabelecida uma conversa com os estudantes, na qual foi seguido um roteiro de entrevista, posteriormente alguns temas gerais foram destacados e os alunos deveriam indicar uma palavra que lhes remetia àquele assunto. Quando eles faziam isso era possível apreender mais diretamente algumas ideias ou aprofundá-las. Os alunos escreviam as palavras no tabuleiro por meio de dados de letras.

Figura 7: Registro do tabuleiro e dados utilizados, escrito ilustrativamente a palavra escola.

${ }^{7} \mathrm{O}$ jogo possui um tabuleiro com algumas letras distribuídas e vários dados também com letras em suas faces, sendo que durante a entrevista os alunos deveriam formular palavras, conforme lhes conviessem, dentro de um tema previamente proposto. 


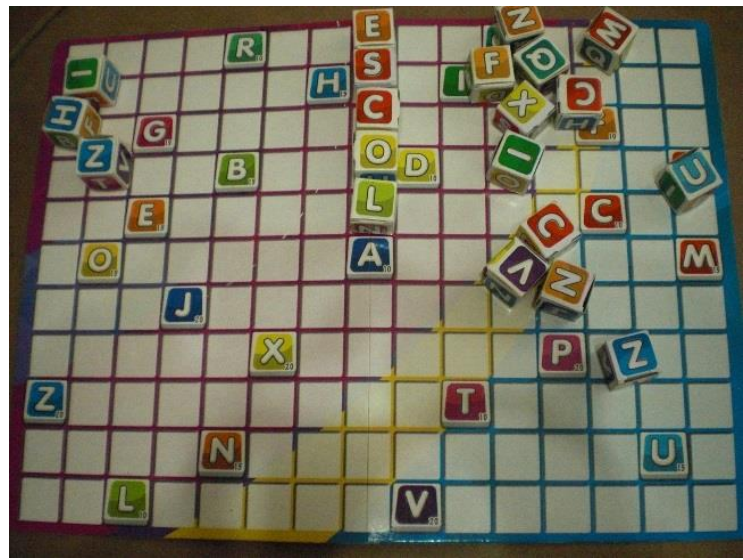

Fonte: Elaboração própria.

Todas as entrevistas foram gravadas e transcritas.

Diante das informações obtidas por meio das entrevistas com professores e alunos e da autobiografia escrita pelos estudantes; leituras e releituras dos materiais foram efetivadas em busca de contradições ou destaque a padrões.

Neste momento, foram enfatizadas as perspectivas dos sujeitos acompanhados sobre os desempenhos escolares indicados como mediano. Em destaque a percepção dos alunos, Mani e Messias, sobre algumas experiências que tiveram ao longo de um período do processo de escolarização deles.

\section{Discussão dos resultados}

Os resultados foram organizados conforme as informações obtidas da Mani e Messias, as quais constam na sequência. Depois, as percepções das professoras foram sistematizadas, relacionando-se com as dos alunos.

Percepções dos alunos sobre os próprios desempenhos escolares

Mani desde os sete anos de idade até os dez anos, afirmou que se considerava uma "boa" aluna, esforçada, inteligente e que realizava as atividades propostas na escola.

Em 2009, Mani considerou que gostava de brincar e de estudar, o que seria possibilitado pela escola, vista de forma positiva pela menina, que se considerava uma aluna esforçada porque estudava; logo tinha um desempenho alto. Inclusive revelou que seus amigos e a professora também lhe diziam isso. Neste momento, Mani disse que almejava ser médica. 
Após dois anos pouco havia se alterado na percepção de Mani sobre a própria frequência à escola. Segundo ela: "Tá a mesma coisa." (Mani, 2011). Em 2011, a menina relatou que continuava a ser uma aluna com alto desempenho, pois sempre realizava as atividades corretamente e notara que outros alunos nem sempre conseguiam fazer tudo que era proposto em sala de aula ou mesmo não tentavam.

Mani informou que gostaria de saber coisas novas e isso lhe era proporcionado pela escola, instituição que se mantinha importante na vida da garota. Ela pretendia estudar antes de trabalhar e passou a querer seguir a carreira de professora.

Sobre a rotina vivenciada por Mani, ela informou que assistia televisão ou brincava em casa. Essas atividades não foram enfatizadas em 2012, já que neste momento ela descreveu o dia-a-dia dela da seguinte forma: "Vô pra casa, almoço, depois vou levar o menino da vizinha pra escola, ai eu volto em casa, faço tarefa, [...] lavo a lousa ou senão fico olhando o menino da vizinha." (Mani, 2012).

Na escola, quando Mani cursava o quinto ano, aos dez anos de idade, ela contou que não simpatizava tanto com a professora, porque: "Ai assim, quando nois vai fazê um texto, ela fala assim que nois não tamo fazendo." (Mani, 2012).

Mani entendia que o desempenho escolar dela permanecia como alto e ainda gostaria de seguir a carreira docente. Pontuou que no próximo ano preferiria estudar em uma escola, porém morava ao lado de outra unidade de ensino, esta era frequentada pela prima, por isto teria que ir para a mesma escola que a prima frequentava; meditou que estudar ali a deixava menos animada para seguir para o Ensino Fundamental II.

De tal maneira, é possível aferir que, até aquele momento, houve manutenção na rotina escolar de Mani e nas percepções sobre o desempenho escolar apresentado por ela, a qual permaneceu cerceada pelo estudo e pela valorização da escola. Já em sua rotina familiar, foi possível notar que a menina passara a ter mais afazeres, ao ajudar no cuidado de crianças da vizinhança e na limpeza da casa ${ }^{8}$.

Com relação ao Messias, foi possível perceber que a percepção dele também se manteve a mesma ao longo do período acompanhado: se entendia como um aluno com alto desempenho escolar. Aos sete anos de idade, Messias cursava o segundo ano escolar. Nesta época, ele relatou que gostava de ir à escola, porque tinha amigos naquele lugar. Revelou que nos primeiros dias de aula, após deixar a escola de Educação Infantil, ele havia ficado um pouco nervoso, porém isso logo foi superado.

${ }^{8}$ Mani não quis escrever o texto proposto à turma para relatar a história dela.

Doxa: Rev. Bras. Psicol. Educ., Araraquara, v.19, n.2, p. 338-354, jul./dez. 2017. 
Messias contou que gostava de ficar com seus pais e com cachorra dele, mas não apreciava brincar na rua. Considerava-se um menino inteligente, bonito e esforçado, que fazia todas as tarefas escolares e estudava. Logo, acreditava que era um aluno com alto desempenho e justificou, "Porque eu sempre sei o que é para fazer." (Messias, 2009). Todavia, também reconheceu que quando precisava escrever ficava um pouco atrasado e não gostava disso.

Desde o primeiro encontro com Messias, ele revelou que pretendia ser arqueólogo, por ser apaixonado por dinossauros ou veterinário, já que gostava de animais.

Em 2011, Messias comentou que apenas a idade dele havia mudado, acreditava que mantinha um alto desempenho por realizar as tarefas e estudar. Inclusive continuava a gostar da escola e nunca pensou que poderia ser reprovado. Ainda planejava seguir a mesma profissão e pretendia estudar por um longo período: "Tem que estudar bastante pra ganhar bastante dinheiro e procurar fonte de dinossauro." (Messias, 2011). Portanto, o garoto manteve os seus planos para o futuro profissional.

Em 2012, corroborando com a análise da mãe dele e com os elogios da professora, Messias pontuou que tinha notado avanços em seu desempenho escolar. Pensou isso "Pelas notas, eu to melhorando cada vez mais [...] eu fiquei mais interessado ainda, to bem interessado." (Messias, 2012). Ele arguiu também que a professora o ajudava a aprender, ensinava bem, chamava os alunos na mesa dela quando tinham dúvidas e que os conteúdos estudados estavam "intrigantes" (utilizou este termo).

Messias também falou que estava animado para mudar de escola, preferia ir para a mesma escola preterida por Mani, mas devido a sua residência, teria que ir para a unidade de ensino que provavelmente a menina também estudaria.

Sendo assim, foi possível perceber que Messias se considerava um aluno com alto desempenho escolar desde 2009, porém em 2012 concluiu que ficou ainda mais interessado pela escola e ele estava animado por iniciar uma nova fase no Ensino Fundamental II.

Em 2012, Messias escreveu o texto proposto para todos os alunos da turma dele, com uma letra impecável e com poucos erros ortográficos.

[...] Gosto de andar de bicicleta, jogar videogame, brinca com brinquedo, desenhar, brincar com meus amigos e apressio muito a leitura.

Sou um menino forte (gordinho), tenho 1,43 de altura, peso 50 quilos, tenho os olhos castanho escuro e sou branco e me acho bonito.

Eu sou bondoso, calmo e amoroso, inteligente, estudioso etc...

Tem uma coisa que eu nunca vou me esquecer, o falecimento da minha avó, mãe do meu pai. 
Eu gosto muito da minha escola, porque lá os professores ensinam de uma maneira fácil.

A minha escola é muito boa, ensina bem, tem bons professores e muitas coisas legais.

Nunca me mudaria da minha escola pois é muito boa.

Meus colegas de sala são bons alunos, porque a minha professora elogia a classe.

Meus pais gostam da escola e me ajudam na vida escola ajudam-me com as lições de casa, me dão dicas sobre a escola e estão sempre presentes.

Moro com meus pais e minha mãe, meu pai trabalha como motorista de caminhão e a minha mãe como cuidadora nossa família e mito feliz.

Eu sou um aluno muito bom pois minhas notas são altas e recebo elogios da professora e dos meus pais.

Nunca fui reprovado, e me sinto orgulhoso e meus pais também se sentem orgulhosos.

Não mudaria nada da minha vida, pois sou muito feliz com ela como ela é.

O meu maior sonho é ir para Disney.

Eu tenho muito medo de altura pois quando estou em um lugar alto parece que tem mais de 1000 metros.

Eu pretendo ser veterinário, porque gosto de animais e quero ter a chance de mantelos com saúde. (Messias, 2012).

O texto escrito por Messias expressou as preferências dele e pôde trazer um registro das percepções que ele apresentou naquele momento, as suas experiências escolares e familiares. $\mathrm{O}$ menino se mostrou motivado frente à escola frequentada e à turma que fazia parte, apreendendo elogios desferidos a ele e ao grupo. $\mathrm{O}$ aluno também comentou sobre o apoio que recebia dos pais para estudar, as dicas sobre o funcionamento da instituição e o alto desempenho que entendia apresentar.

\section{Percepções dos professores sobre o desempenho escolar de Mani e Messias}

Os dados encontrados por meio deste estudo indicaram que as percepções das distintas professoras que ministraram aulas para Mani e Messias, mantiveram um padrão de análise frente a cada aluno. Não houve variações significativas diante das apreciações dos desempenhos deles no decorrer do período acompanhado, afinal, em geral, foram apontadas características aproximadas sobre os estudantes, localizando diferenças ênfase dada pelas docentes a esses atributos.

O que corrobora com Lahire (1997) ao entender que os "julgamentos" dos professores, diante de estudantes, registravam comportamentos reais, porém, sobressaíam nitidamente uma seleção de fatos e gestos pertinentes ou não, construindo perfis que associavam comportamentos morais e resultados escolares. 
Assim, embora tenha predominado concordâncias entre os professores que ministraram aulas para os alunos, também foi possível perceber algumas variações, em que determinados comportamentos dos alunos foram selecionados pelos docentes e/ou enfatizados.

Mani e Messias foram indicados, em 2009, como alunos com desempenhos medianos. Neste mesmo momento, ao final do ano, a professora que ministrou aulas para a turma de Mani passou a entendê-la como uma estudante com alto desempenho, em 2011 ela foi posta entre uma das melhores alunas do grupo, porém em 2012 passou a ser analisada novamente como um caso de desempenho mediano. As professoras, em 2009 e 2011, se mostraram comovidas devido ao fato da estudante vivenciar problemas familiares (morar com os avos e os pais estarem presos) e mesmo assim apresentar comportamentos adequados e ser estudiosa, constituindo um caso atípico, o que não foi citado pela professora em $2012^{9}$.

Romanelli (2013, p.54) notou que as pesquisas sobre fracasso escolar, de certa forma, cederam espaço para questões pautadas no sucesso e longevidade nas trajetórias escolares nas camadas populares, aspecto que pode ser questionado: "Os casos de sucesso escolar, particularmente nas famílias de camadas populares, são tão expressivos ou a opção por tal temática encobre questões teóricas e mesmo ideológicas e políticas que merecem uma interpretação mais acurada?" Os dados obtidos por meio do presente estudo indicaram que, dentre outros aspectos, os casos atípicos despertariam também os interesses dos professores, os quais desenvolviam uma espécie de admiração aos comportamentos despendidos por estes alunos.

Messias não vivenciava em seu contexto familiar conflitos que despertassem a atenção dos professores. Em 2009 e 2011 existiram concordâncias entre as percepções docentes, visto que o garoto foi entendido como um aluno que realizava as atividades escolares, mas às vezes, se mostrava sonolento e apático nas aulas, precisando de um tempo maior para concretização das propostas. Após um ano, Messias ainda foi destacado como um menino que realizava as atividades e precisava de um tempo maior do que o restante do grupo para isso, entretanto, foi anunciado que o garoto conseguia manter relacionamentos positivos com os colegas de turma, além de ser capaz de explicar como pensava para realizar atividades, o que o tornou um aluno com alto desempenho escolar, na percepção da professora corroborando com a mãe dele e com o próprio estudante. 
Vale pontuar que nos casos de Mani e Messias, as responsáveis e os próprios alunos afirmaram que os desempenhos escolares apresentados eram alto desde 2009. Sendo atribuído em 2012 ao Messias, pela mãe dele e por ele mesmo, elogios mais intensos, "estava ainda melhor".

Os dados apresentados por esta pesquisa concordam com Zago (2000), Viana (2000), Portes (2001), Streib (2011) e Calarco (2011) ao entenderem os alunos acompanhados como sujeitos ativos ao longo do processo de escolarização em que foram acompanhados, afinal eles se posicionaram diante das experiências escolares e reconheceram ações valorizadas pela instituição de ensino, como ao realizarem atividades propostas, estudar, saber o que deveria ser feito, além de valorizarem e gostarem da escola.

Sendo assim, foi possível concluir que os alunos nem sempre concordaram com as indicações docentes de que eles seriam estudantes com desempenho mediano, visto que eles acreditavam ter um alto desempenho escolar. Os professores que ministraram aulas para tais alunos, no decorrer do período acompanhado apresentaram um padrão de análise comum do desempenho escolar dos alunos, pontuando uma sutil mudança no $5^{\circ}$ ano, quando a docente entendeu que o Messias tinha um alto desempenho (diferente das docentes no $2^{\circ}$ e $4^{\circ}$ anos).

\section{Considerações finais}

Este texto teve como objetivo apreender a percepção de duas crianças/alunos sobre as experiências e desempenhos escolares apresentados por eles no decorrer de parte de suas trajetórias no Ensino Fundamental I e relacionar tais percepções a de professores que ministraram aulas para eles.

Foi possível concluir que Mani e Messias expuseram suas percepções sobre os desempenhos escolares e experiências vivenciadas no contexto escolar, as quais nem sempre corroboraram, plenamente, com indicações dadas por professores, já que os estudantes mantiveram, desde 2009, a percepção de que apresentavam um alto desempenho escolar, porque recebiam elogios e sabiam realizar as propostas da instituição de ensino. Ressalta-se que em 2012 o garoto notou uma mudança ao relatar progressos no desempenho escolar dele. Sobre isso, vale acrescentar que as percepções de diferentes professores sobre as referidas crianças/alunos mantiveram padrões de análise bastante próximos, sendo que assim como apontado pelo menino, a responsável pelo quinto ano também o analisou como um caso de alto desempenho escolar. Os dois alunos/crianças demonstraram preocupações com a 
possibilidade de acesso a determinadas escolas em detrimento de outras na sequência do processo de escolarização.

Por fim, mostra-se importante sinalizar que trata-se de um estudo de caso, qualitativo, que precisa de outras investigações atentas às trajetórias escolares para que possam aprofundar a temática.

\section{REFERÊNCIAS}

ABRANTES, P. As transições entre ciclos de ensino: entre problema social e objecto sociológico. Interacções, Lisboa, n.1, p.25-53, 2005.

ARIÈS, P. A história social da criança e da família. 2.ed. Rio de Janeiro: LTC, 1981.

BOGDAN, R.; BIKLEN, S. Investigação qualitativa em educação: uma introdução à teoria e aos métodos. Porto: Porto Ed., 1994.

BRASIL. Lei n.8.069, de 13 de julho de 1990. Dispõe sobre o Estatuto da Criança e do Adolescente e dá outras providências. Diário Oficial da União: República Federativa do Brasil: Poder Legislativo, Brasília, DF, 16 jul. 1990. Disponível em: <http://www.planalto.gov.br/ccivil_03/leis/L8069.htm>. Acesso em: 21 nov. 2017.

CALARCO, J. M. I need Help!: social class and children's help seeking in elementary school. American Sociological Review, Washington, v.76, n.6, p. 862-882, 2011.

GIMENO SACRISTÁN, J. O aluno como invenção. Porto Alegre: ARTMED, 2005.

GIRALDI, L. P. B. Percepções sobre trajetórias escolares de alunos do ensino fundamental: os contextos, os tempos e as relações. 2014. 364f. Tese (Doutorado em Educação Escolar) - Faculdade de Ciências e Letras, Universidade Estadual Paulista, Araraquara, 2014. Disponível em:

<https://repositorio.unesp.br/bitstream/handle/11449/115980/000809885.pdf? sequence=1>. Acesso em: 21 nov. 2017.

GIRALDI, L. P. B. Os níveis diferenciados de desempenho escolar: analisando estabilidade e mudanças nas concepções e expectativas de professores, familiares e alunos. 2010. $255 \mathrm{f}$. Dissertação (Mestrado em Educação Escolar) - Faculdade de Ciências e Letras de Araraquara, Universidade Estadual Paulista, Araraquara, 2010.

HAKIM, C. Research design: strategies and choices in the design of social research. London: Routledge, 1997.

KRAMER, S. A infância e sua singularidade. In: BEAUCHAMP, J.; PAGEL, S. D.; NASCIMENTO, A. R. do. (Org.) Ensino fundamental de nove anos: orientações para a inclusão da criança de seis anos de idade. Brasília: Ministério da Educação, Secretaria de Educação Básica, 2007. p.13-32.

LAHIRE, B. Retratos sociológicos: disposições e variações individuais. Porto Alegre: ARTMED, 2004. 
LAHIRE, B. Sucesso escolar nos meios populares: as razões do improvável. São Paulo: Ática, 1997.

PAYET, J. P. A escola e a modernidade: o risco da etnicidade, o desafio da pluralidade.

Análise social, Lisboa, v.40, n.176, p.681-694, 2005.

PORTES, É. A. Trajetórias escolares e vida acadêmica do estudante pobre da UGMG: um estudo a partir de cinco casos. 2001. 267f. Tese (Doutorado em Educação) - Universidade Federal de Minas Gerais, Belo Horizonte, 2001.

ROMANELLI, G. Levantamento crítico sobre as relações entre família e escola. In: ROMANELLI, G.; NOGUEIRA, M. A.; ZAGO, N. (Org.). Família e escola: novas perspectivas de análise. Petrópolis: Vozes, 2013. p.29-60.

SARMENTO, M. J. Gerações e alteridade: interrogações a partir da sociologia da infância. Educação e Sociedade, Campinas, v.26, n.91, p.361-378, maio/ago. 2005. Disponível em: <http://www.scielo.br/pdf/es/v26n91/a03v2691.pdf>. Acesso em: 21 nov. 2009.

STREIB, J. Class Reproduction by four year olds. Qualitative Sociology, Ann Arbor, v.34, p.337-352, 2011.

VIANA, M. J. B. Longevidade escolar em famílias de camadas populares: algumas condições de possibilidade. In: NOGUEIRA, M. A.; ROMANELLI, G.; ZAGO, N. (Org.). Família e escola: trajetórias de escolarização em camadas populares. Petrópolis: Vozes, 2000. p.47-60.

ZAGO, N. Processos de escolarização nos meios populares: as contradições da obrigatoriedade escolar. In: NOGUEIRA, M. A.; ROMANELLI, G.; ZAGO, N. (Org.).

Família e escola: trajetórias de escolarização em camadas populares. Petrópolis: Vozes, 2000. p.17-43.

\section{Como referenciar este artigo}

GIRALDI, Luciana Ponce Bellido. As trajetórias escolares: percepções de crianças/alunos e professoras. Doxa: Rev. Bras. Psicol. Educ., Araraquara, v.19, n.2, p. 338-354, jul./dez. 2017. e-ISSN: 2594-8385.

Submetido em: 02/10/2017

Aprovado em: 18/11/2017 